\title{
The Effectiveness of the Inquiry and Brain Storming Strategies in Developing Achievement and Creative Thinking Skills in Arabic Language of University Students
}

\author{
Ahmad Abdullah Asiri ${ }^{1}$ \\ ${ }^{1}$ Head of Joint Programs \& College of Education, King Khalid University, Abha, Saudi Arabia \\ Correspondence: Ahmad Abdullah Asiri, King Khalid University, Abha, Saudi Arabia. E-mail: \\ ahmad.asiri@gmail.com
}

Received: November 7, 2020

Accepted: December 20, 2020

Online Published: December 31, 2020

doi:10.5539/ijel.v11n1p253

URL: https://doi.org/10.5539/ijel.v11n1p253

\begin{abstract}
The study aimed to investigate the effectiveness of using inquiry and brainstorming strategies in teaching Arabic language for developing achievement and creative thinking skills of the university students. To achieve the previous objective, a teaching manual was prepared using inquiry and brainstorming strategies. Achievement test was prepared including 20 items multiple chooses questions related to knowledge, application and reasoning levels. In addition, creative thinking skills test was prepared including 10 items related to Fluency, flexibility and originality skills. The validity and reliability of the instruments were measured. The sample was selected randomly; it consists of two groups, experimental group 43 and a control group 39. The study was based on semi-experimental design pre-post-test, where the experimental group was taught using inquiry and brainstorming strategies, but the control group was taught using the usual strategies. The results of the study showed that there were statistically significant differences between the average scores of the experimental and control groups in the post achievement and creative thinking skills in general and their skills separately for the students of the experimental group. Also, the results showed a positive correlation between the scores of the experimental group in post creative thinking skills, and post achievement test in general. The effectiveness of inquiry and brainstorming strategies in the development of achievement levels and creative thinking skills was significant effect. The study recommended using the Inquiry and brainstorming strategies in the teaching Arabic language of university students.
\end{abstract}

Keywords: creative thinking, inquiry and brainstorming strategies, teaching Arabic

\section{Introduction}

\subsection{Introduce the Problem}

Creative thinking is among the twenty-first century skills that must be integrated into the teaching and learning processes and activities at the program and Courses at all phases of education. Therefore, the development and measurement of creative thinking skills are among the main objectives of teaching and learning processes in all educational programs. Creative thinking supports students of the development of personal effectiveness, enhances problem-solving processes, develops many skills and abilities (Robson, 2014).

The activities and processes of developing the creative thinking, as one of the skills of the 21 st-century, start from a set of principles that emphasize the importance of employing student-centered teaching and learning strategies. The study of Mohammed (2015, p. 24) identified a set of foundations for developing creative thinking skills according to the following:

- Students are seen as knowledge creativer. They can explorers their learning.

- Educators are enablers and companions in the students' learning within a culture of listening.

- Learning is focused on process of the students' explorations.

- Reflecting is very important method to develop creative thinking skills of the students.

- Developing a creative learning community enhances the students to develop creative thinking.

- $\quad$ Posing daily life problems supports learning of the students. 
- Asking the questions helps the student to think and learn.

- Students can choose their own methods of thinking and learning.

The development of creative thinking skills is associated with choosing strategies that support students in drawing on past experiences, describing relationships, and forming new ones. Also, teaching strategies must support students in process of generativity; nonjudgment; and expansiveness. Among the most important strategies that support the development of students' creative thinking skills are problem-solving strategies, investigation, brainstorming, and discussions within learning communities (McCarthy, 2018).

Also, Language teaching processes face many challenges, the most important of which is the continued use of traditional, direct strategies that rely on direct presentation, and focus on presenting grammar. These strategies do not enhance students' meaning-building, and reduce opportunities for language applications. On the other side, there is relationship between developing thinking and building language skills. It was necessary to employ teaching strategies that take into account the needs of students. Inquiry-based teaching strategies are among the strategies that enhance students' linguistic needs. They start from the premise that language is a social thinking activity that requires processes of reading, research and deduction of meaning, identifying new vocabulary and ideas, and deducing linguistic generalizations, while employing them in developing reading and writing skills.

There is relationship between the inquiry strategy and with the development of creative thinking skills. The inquiry strategy Supports students in uncovering the real world through planning educational situations related to life situations. The inquiry strategy includes many modern strategies in its steps and processes, including problem solving and classroom discussions. Inquiry strategy can be used in natural subjects, languages and the social sciences (Memory et al., 2004). The use of the inquiry strategy helps the teacher in re-planning learning experiences, moving from abstract concepts to real experiences that stimulate students towards discovering relationships, building patterns and building inferences. Inquiry strategy helps students build an open mind through searches processes, reflection and notes writing. These processes enhance the development of students' creative thinking skills (Carstens \& Howell, 2012). Also a study of Kiili (2019) showed the effectiveness of the survey strategy because it can be employed individually or in pairs. This strategy provides opportunities for students to communicate and discuss ideas, and promotes self-learning with teacher guidance.

The main function of teaching and learning strategies is related to simply providing scientific content and its components. These strategies enable students to assimilate this scientific content. Contemporary trends in teaching and learning have moved from direct learning strategies to active learning strategies, and include many strategies, including inquiry-based learning and brainstorming. These strategies start from a set of principles, the most important of which are the following (Tomcho et al., 2008):

- The process of building knowledge is an active process,

- Knowledge building is a social process,

- Knowledge building requires student activity,

- Building knowledge requires mastering language skills,

- Knowledge building is a mental and performance process,

- Building knowledge is a thoughtful process,

- Knowledge building is an interactive process among students,

Language activities in university education aim to build the capabilities of the university student in basic language skills, especially reading and writing. And related to this are many advanced skills in language, including: comprehending the read text and building the accurate meaning, and writing correct scientific articles in the light of the standards of scientific writing. Inquiry-based learning is one of the teaching strategies that enhance the building of students' language communication through the processes of searching for new vocabulary, understanding meaning from context, using vocabulary in conversations, writing notes, writing and reviewing articles, and communicating with other students in correct ways. In addition to the above, inquiry-based learning enhances students in developing many thinking skills, As follows (Moses, Busetti, \& Pritchard, 2015):

- Inquiry encourages higher-level thinking,

- Deepening their thinking,

- Inquiry supports the development of questioning, thinking, and creating, 
- Inquiry enhances research skills.

In addition to the above, the study of Coskun and Gocmen (2019) confirms the effectiveness of the brainstorming strategy in developing creative thinking skills. Creativity is often required to generate new solutions in many areas of life such as from ordinary life situation to highly specialized research and development team situation. As the best-known creativity technique, brainstorming technique provides some beneficial rules like no criticism, unusual ideas are welcome, the quantity of ideas is wanted over quality of ideas and idea combination is sought for a higher creativity in groups. However, groups do not get benefit from these rules since free-riding, production blocking, evaluation apprehension, and downward-matching are mostly evident in the brainstorming groups as compared to nominal groups who brainstorm individually. As known, in the individual brainstorming technique, the participants generate ideas by oneself.

The previous studies and literature have emphasized the importance of improving academic achievement levels and developing creative thinking skills in the language skills course. Also, the previous studies and literature have emphasized the importance and effectiveness of using inquiry-centered learning and brainstorming strategies to teach in developing academic achievement levels and developing creative thinking skills.

\subsection{Problem of This Study}

A lot of studies, including studies of Sak and Maker (2006), Coles and Banfield (2012), Anjarwati, Sajidan and Prayitno (2018), Ritter et al. (2020), have confirmed that low levels of students' academic achievement and creative thinking skills are refer to teaching strategies. Traditional teaching strategies are related to the direct presentation of learning experiences, and do not support the student in developing multiple and varied paths of thinking. Also, direct learning strategies focus on learning outcomes, and do not focus on the learning and instruction processes, practices and activities carried out by the student. These processes are very necessary for developing creative thinking skills and improving academic achievement levels.

In a language skills course, the researcher observed that students respond to traditional questions associated with lower levels of thinking. However, students do not respond to questions related to measuring higher levels of thinking, especially levels related to creative thinking skills in Arabic language skills. So the problem of the current study is determined in the low levels of university students in achievement and creative thinking skills in the Arabic language. The reasons of this problem are identified in the traditional teaching strategies used by university professors in teaching Arabic language courses. This teaching strategy depends on the direct presentations, and the focus on scientific content. In order to solve the current problem, the study aims to answer the following questions:

\subsection{Questions of This Study}

- How can Inquiry and brainstorming strategies be used in teaching Arabic to develop achievement and creative thinking skills for university students?

- What is the effectiveness of the Inquiry and brainstorming strategies in developing achievement in the Arabic language among university students?

- What is the effectiveness of the Inquiry and brainstorming strategies in developing creative thinking skills in the Arabic language among university students?

- What is the relationship between university students' degrees in achievement in the Arabic language and their degrees in creative thinking skills?

\subsection{Purpose of This Study}

The main goals of this study are developing achievement and creative thinking skills in Arabic language of university students through using the Inquiry and brainstorming strategies in teaching. Also investigate the effectiveness the Inquiry and brainstorming strategies in teaching Arabic language, and the relation between the achievement and creative thinking skills.

\subsection{Scope of This Study}

- The target group of this study consisted of 82 students at King Khalid University to investigate the effectiveness of inquiry and brainstorming for teaching Arabic language in developing achievement and creative thinking skills.

- Part of the subject of the language skills course, which was studied during the first semester of academic year 2019 in the preparatory year.

- Research variables consist of, 1) Independent variables that is the inquiry and brainstorming strategies 
and, 2) Dependent variables are achievement and creative thinking.

\subsection{Theoretical Framework}

Mastery of 21 st-century skills is crucial for future education. The application of these skills in learning is expected to trigger students to be able to overcoming their challenges and competitiveness in the globalization. In line with the opinion by searchers that in the 21 st-century students are not only judged by the ability to answer questions but also to assess the extent of their ability and knowledge in using the skills they possess. The skills can be trained through cognitive activity such as problem-solving, critical thinking, and creative thinking. Creative thinking is one of the 21 st-century skills that are essential for long-term success. Creative thinking becomes a fundamental need for one's success. Creative thinking could make students look for other alternatives in a different perception, concept, and general knowledge. There is strong relationship between developing creative thinking skills and improving other thinking skills. In conclusion, developing creative thinking skills are very important to improve a lot of skills of the students to enhance and help them living in the 21st-century. (Anjarwati, Sajidan, \& Prayitno, 2018).

Creative thinking skills are mental phenomenon that results from the application of ordinary cognitive processes such as working memory, the ability to categorize and manipulate objects, creative cognition approach, create knowledge paths. The ability to think creatively can be taught and developed for the students' through using teaching practices and strategies. The teachers have to change their teaching practices, and move from traditional teaching strategies to learning based students which confirm student positivity in learning situations. In fact, the traditional teaching strategies don't enhance the teacher and the students in developing creative thinking skills, developing thinking skills in general and academic achievement levels (Ritter et al., 2020).

The definition of creative thinking is related to fluency, flexibility, originality and novelty in solving real life problems. It is also related to the level of achievement that the student attains in thinking, especially the method and level of thinking. The practices of developing and measuring creative thinking skills depend on a set of characteristics that can be observed among students, the most important of which are: Searching for complex meanings in the reading text, searching for alternatives in solving the problem, accepting the calculated challenge and risk, retrying the thinking and learning processes, the tendency to ambiguous situations, Trying out ideas, Speculating, and the ability to deal with various educational resources abilities (Robson, 2014).

Creativity development practices depend on teaching strategies that develop the imagination and support students in developing cross-thinking skills. Creative thinking is directly related to the student's ability to imagine and construct the mental images involved in language teaching and learning. Creativity development is linked to rich educational experiences, open and varied educational resources, and educational environments based on freedom of discussion, expression and brainstorming. The process of developing creative thinking depends on a set of elements in the educational environment like boundary-break, unconventionality, new facts concepts and skills in learning, training the students to think, experiences that related to the senses not abstract (Nogueira, Almeida, \& Lima, 2017).

On the possibility of developing creative thinking skills, there are a set of teaching practices and strategies that support students in developing creative thinking skills, according to the following (Valentová \& Brečka, 2020):

- Encourage the students towards acquiring concept and skills.

- Using a lot of teaching strategies related to the students and subject.

- Using technical materials to enhance the learning process.

- Posing learning situations that induce using the product creation

- Encourage the students in thinking processes and creativity.

- Developing the main ideas and discuss it in small and whole group.

- Using teaching strategies for developing creativity.

In addition, learning in the 21 st-century according to should be held in a collaborative, creative thinking skills, and innovative strategies. The teachers should plan and prepare the teaching lessons holistically and practices to facilitate students in contextual, participatory, active, and creative learning. Creative thinking is related to the student's production of new ideas, solutions, or hypotheses. It requires educational practices and activities that reinforce these processes in students. The strategy of brainstorming is one of the teaching strategies that stimulate students' thinking processes, make the students activation on the idea generation and support students towards producing diverse ideas. This strategy can be used in small or large groups, and it can be used in a variety of courses, and in discussing unfamiliar educational situations (Coskun \& Gocmen, 2019). 
Inquiry-based learning is one of the learning strategies that have been used in science teaching, and have proven effective in all subjects, especially subjects that depend on developing skills, and discovering the necessary rules for developing these skills. Inquiry-based learning can be more effective than direct forms of instruction (Vreman-de, Ton, \& Gijlers, 2013).

The importance of using inquiry-based learning is to stimulate student participation in teaching and learning activities. Furthermore, using inquiry-based learning enhances the students to think theought the processes of research, investigation, and thinking about applying the knowledge they have acquired in real situations. Inquiry-based learning also enhances the processes of inquiry, deduction, participation in learning planning, building positive attitudes, and processes of persistence in thinking and learning (Evans \& Lange, 2019). Also, inquiry-based learning is related to Student-centered learning (Paula \& Wingate, 2014).

In addition, inquiry-based learning integrates many strategies throughout its steps, its components, and associated teaching practices, including problem-solving, brainstorming and discussions in collaborative groups (Dunlap \& Antonio, 2012). Furthermore, there are set of skills related to developing creative of the students' through using inquiry-based learning and brainstorming as follows (Tomcho et al., 2008, Ormond, 2011):

- Descriptive skills: observation, measurement, and interpretation.

- Conceptualization skills: recognizing and applying concepts, recognizing and applying basic theory, and advanced skills in evaluating, synthesizing, or generating theory.

- Problem-solving skills: recognizing, applying, or generating methods skills; recognizing, applying, evaluating or generating statistical reasoning; and bias detection and management.

- Ethical reasoning skills: awareness of ethical standards, evaluation of ethical practices, and adherence of ethical standards.

- Scientific attitudes and values incorporating: enthusiasm for research, objectivity/subjectivity, parsimony, skepticism, and ambiguity tolerance.

- Communication skills: selecting appropriate resources, argumentation prowess, and use of conventional expression.

- Collaboration skills: completing projects, process management, and leadership, consensus building skills, and brainstorming.

- Self-assessment skills: self-regulation and self-reflection.

- Developing students' Deeping and meaningful understanding.

Inquiry-based learning provides an opportunity for students to visualize experiment, apply knowledge, and apply skills continuously. Inquiry-based learning can be employed in all scientific and social subjects, as it is related to supporting students in the processes of discovery and building knowledge according to their abilities and preferences (Pittman, 2011, p. 5; Baker et al., 2008).

It is noted that the inquiry-based learning and brainstorming strategies are related to the development of creative thinking skills. Inquiry-based learning strategy focuses on building processes of discovery, generating alternatives, testing hypotheses, and applying knowledge, while brainstorming strategy focuses on stimulating students' mental stimulation and producing ideas and alternatives. It also notes that the Inquiry-based learning and brainstorming strategies are related to language learning and language development (listening, speaking, reading and writing), as they allow training in reading texts, comprehending meanings, building vocabulary and structures, and developing creative writing skills.

\section{Method}

\subsection{Research Design}

The study aims to explore the effectiveness of inquiry and brainstorming strategies in developing achievement and creative thinking. This study depends on the semi-experimental approach (pre-post) tests. The achievement test and the creative thinking skills test were applied pre, and the experimental group was studying the language skills course using the strategies of brainstorming and inquiry-centered learning, while the control group was studying using the usual strategies. In addition, the achievement test and the creative thinking skills test were applied to study effectiveness.

\subsection{Participants}

The current study population consisted of all students of the preparatory year at King Khalid University, who are 
studying the language skills course (2-credi thours). The study sample consisted of two groups, an experimental group (43, 23 male and 20 female students), and a control group (39, 19 male and 20 female students).

\subsection{Data Collection Procedures}

\subsubsection{Teaching Strategies}

The current study relied on employing my strategy in teaching Arabic through a set of steps. Table 1 shows the teaching and teaching practices of the university professor and students in learning the Arabic language:

Table 1. Teaching practices of the Inquiry-based learning and brainstorming strategies

\begin{tabular}{|c|c|}
\hline teaching & Teaching practices \\
\hline open the idea & $\begin{array}{l}\text { - } \quad \text { Present life situation, image, written text, or short story. } \\
\text { - } \quad \text { Encourage students to interact with the scientific material } \\
\text { - } \quad \text { Discuss the content of the scientific material using Brainstorming. }\end{array}$ \\
\hline Problem or questions posing & $\begin{array}{l}\text { Encouraging students to pose specific problems and questions by interacting with the scientific } \\
\text { material } \\
\text { - Writing problems and questions while identifying duplicate ideas and original ideas }\end{array}$ \\
\hline Discussion and productivity & $\begin{array}{l}\text { - Motivate students to work collaboratively to solve problem and answer questions (prove them by } \\
\text { educational resources) } \\
\text { - Determine grammar and how to use it during verbal discussions, reading texts, and writing ideas } \\
\text { and solutions } \\
\text { - } \quad \text { Participation of students in the standards of writing texts correctly. }\end{array}$ \\
\hline Investigation and reasoning & $\begin{array}{l}\text { - } \quad \text { Solve the situation and present solutions using language skills } \\
\text { - } \quad \text { Deduction of new grammatical rules in both read and written texts } \\
\text { - } \quad \text { Correctly apply grammar rules in new situations }\end{array}$ \\
\hline
\end{tabular}

To achieve the goals of the current study, a set of presentations of the language skills course topics were prepared for students of the preparatory year at King Khalid University. The teaching practices associated with the inquiry-centered learning strategies and brainstorming was used as in the steps shown in Table 1. The topics included the four language skills as speaking, listening, reading and writing included in the course topics for the first semester of the academic year 2019/2020.

\subsubsection{Measures: Academic Achievement Test}

The academic achievement test was prepared to investigate the effectiveness of the inquiry and brainstorming strategies in developing the levels of achievement. The test was prepared depending on analyzing the previous studies including developing and measuring the academic achievement. The process of measuring academic achievement included dimensions of knowledge, application and reasoning. The test of achievement included 20 items multiple-choses. Table 2 shows the test specifications as follows:

Table 2. Description of the academic achievement test's dimensions

\begin{tabular}{llc}
\hline Dimensions & Description of the dimensions & Items \\
\hline Academic Achievement Test & Understand and define grammatical rules in the read or written text, in addition to reading comprehension. & 6 \\
\hline Knowledge & Using the grammar in the written text through the process of text analysis or an educational situation. & 6 \\
Application & Deducing grammatical rules by analyzing the models presented in the written texts, with building linguistic & 8 \\
Reasoning & texts according to the correct grammar. & \\
\end{tabular}

Achievement test questions were formulated from the multiple-choice items, and the questions were directly related to the course topics.

\subsubsection{Measures: Creative Thinking Skills Test}

The creative thinking skills test was prepared to investigate the effectiveness of the inquiry and brainstorming strategies in developing creative thinking. The studies related to developing and measuring the creative thinking skills was investigated to describe the dimensions. The dimensions of measuring creative thinking test were related to Fluency, flexibility and originality skills. The test includes 10 items. Table 3 shows the creative thinking skills test specifications as follows: 
Table 3. Description of the creative thinking skills test's dimensions

\begin{tabular}{lll}
\hline Dimensions & Description of the dimensions & Items \\
\hline Fluency & $\begin{array}{l}\text { Write multiple ideas about a situation, story picture, or written text, or match the correct creative writing } \\
\text { rules. }\end{array}$ \\
$\begin{array}{ll}\text { Flexibility } \\
\text { Originality }\end{array}$ & Write various ideas about a situation, story picture, or written text, or use the correct creative writing rules. & \\
\hline
\end{tabular}

The questions of the creative thinking skills test were formulated in the form of problems, life situations or open-ended questions related to writing ideas and paragraphs, taking into account the rules for using the language included in the course topics. Each question in the creative thinking skills test was corrected according to the following indicators:

- Fluency: One score for each idea that the student writes in the question. The student gets number of score equals to the number of ideas.

- Flexibility: One score for each idea the student writes in the question. The student gets number of score equals to the number of ideas with no repetition.

- Originality: One score for each new idea that the student writes in the question, provided that its frequency is less than $5 \%$ among students.

\subsubsection{Validity and Reliability of Instruments}

The validity of the achievement test and validity of creative thinking skills were calculated to determine the question's level of measurement for a goal or skill. Also, the internal consistency validity of tests was calculated using the Pearson correlation coefficient between the question score and the total score on the test. Table 4 shows the results of the internal consistency tests for achievement and creative thinking skills:

Table 4. Internal consistency tests for achievement

\begin{tabular}{llllllll}
\hline NO. & R & NO. & R & NO. & R & NO. & R \\
\hline 1 & $0.67^{* *}$ & 6 & $0.71^{* *}$ & 11 & $0.75^{* *}$ & 16 & $0.78^{* *}$ \\
2 & $0.74^{* *}$ & 7 & $0.84^{* *}$ & 12 & $0.66^{* *}$ & 17 & $0.88^{* *}$ \\
3 & $0.71^{* *}$ & 8 & $0.67^{* *}$ & 13 & $0.73^{* *}$ & 18 & $0.70^{* *}$ \\
4 & $0.69^{* *}$ & 9 & $0.83^{* *}$ & 14 & $0.66^{* *}$ & 19 & $0.77^{* *}$ \\
5 & $0.82^{* *}$ & 10 & $0.82^{* *}$ & 15 & $0.64^{* *}$ & 20 & $0.74 * *$ \\
\hline
\end{tabular}

Table 5. Internal consistency tests for achievement and creative thinking

\begin{tabular}{llll}
\hline NO. & R & NO. & R \\
\hline 1 & $0.77^{* *}$ & 6 & $0.71^{* *}$ \\
2 & $0.74^{* *}$ & 7 & $0.69^{* *}$ \\
3 & $0.74^{* *}$ & 8 & $0.66^{* *}$ \\
4 & $0.69^{* *}$ & 9 & $0.75^{* *}$ \\
5 & $0.72^{* *}$ & 10 & $0.81 * *$ \\
\hline
\end{tabular}

In addition, the reliability of the achievement test and creative thinking skills test were measured using Cronbach's alpha coefficient to measure inter-item consistency. Table 5 shows the Cronbach alpha coefficients at the level of dimensions of each test and the total score of the test:

\subsubsection{Study Procedures}

The field study procedures were carried out in light of a set of steps. The first step is to study the equivalence of the experimental and control groups. Study tools were applied before the main experiment. The results were as follows: 
Table 6. Means, standard deviations and (t-test) to study the differences between the experimental and control groups in the pre application of the achievement test

\begin{tabular}{llllllll}
\hline dimensions & Groups & $\mathrm{N}$ & means & Std. deviation & (t-test) & df. & Sig. \\
\hline Knowledge & experimental & 43 & 2.42 & 1.02 & 1.114 & 80 & 0.269 \\
& control & 39 & 2.67 & 0.98 & & & \\
Application & experimental & 43 & 2.47 & 0.91 & 1.054 & 80 & 0.295 \\
& control & 39 & 2.26 & 0.88 & & & \\
Reasoning & experimental & 43 & 2.09 & 0.68 & 0.269 & 80 & 0.789 \\
& control & 39 & 2.05 & 0.72 & & & \\
Total & experimental & 43 & 6.98 & 1.37 & 0.008 & 80 & 0.994 \\
& control & 39 & 6.97 & 1.48 & & & \\
\hline
\end{tabular}

Table 6 shows that there are no differences between the experimental and control groups in the means in the pre application of the achievement. As shown in Table 6 there is no statistical significance of (T-test). So it is concluded that, There were no statistically significant differences at $(\alpha \leq 0.01)$ between the scores means of experimental and control groups in the pre-application of achievement test in general, and in each of its dimensions alone. The current result indicates the equivalence of the two study groups, the experimental group and the control group.

Table 7. Means, standard deviations and (t-test) to study the differences between the experimental and control groups in the pre application of the creative thinking test

\begin{tabular}{llllllll}
\hline dimensions & groups & $\mathrm{N}$ & Means & Std. deviation & (t-test) & df. & Sig. \\
\hline Fluency & experimental & 43 & 21.96 & 1.79 & 0.681 & 80 & 0.498 \\
& control & 39 & 21.59 & 1.80 & & & \\
Flexibility & experimental & 43 & 16.84 & 1.61 & 0.731 & 80 & 0.467 \\
& control & 39 & 16.59 & 1.42 & & & \\
\multirow{2}{*}{ Originality } & experimental & 43 & 4.07 & 1.38 & 0.110 & 80 & 0.913 \\
& control & 39 & 4.10 & 1.31 & & & \\
\multirow{2}{*}{ Total } & experimental & 43 & 42.77 & 2.91 & 0.764 & 80 & 0.447 \\
& control & 39 & 42.28 & 2.82 & & & \\
\hline
\end{tabular}

Table 7 shows that there are no differences between the experimental and control groups in the means in the pre application of the creative thinking skills. As shown in Table 7 there is no statistical significance of (T-test). So it is concluded that, There were no statistically significant differences at $(\alpha \leq 0.01)$ between the scores means of experimental and control groups in the pre application of creative thinking skills test in general, and in each of its dimensions alone. The current result indicates the equivalence of the two study groups, the experimental group and the control group.

The main procedure of this study was applied the teaching practices and strategies. This step lasted for two months in the first academic year. The experimental group was studied using inquiry and brainstorming, and the control group was studied with usual strategies centered on direct presentation, explanation and exercises. Study tools were also applied after teaching. Several statistical tests were used to study the differences, including the (T-test), with the use of methods of measuring effectiveness.

\section{Results}

\subsection{Academic Achievements}

The question: What is the effectiveness of the Inquiry and brainstorming strategies in developing achievement in the Arabic language among university students? To answer the current question, the following hypothesis has been formulated: There were statistically significant differences at $(\alpha \leq 0.01)$ between the scores means of experimental and control groups in the post application of achievement test in general, and in each of its dimensions alone in favor of the experimental group. Also, the means, standard deviations, and (t-test) value were calculated. The results were as shown in Table 8. 
Table 8. Means, standard deviations and (t-test) to study the differences between the experimental and control groups in the post application of the achievement test

\begin{tabular}{lllllllll}
\hline dimensions & groups & $\mathrm{N}$ & means & Std. deviation & (t-test $)$ & df. & Sig. & $\left(\eta^{2}\right)$ Eta squared \\
\hline Knowledge & experimental & 43 & 5.56 & 0.54 & 6.699 & 80 & $0.000^{* *}$ & 0.359 \\
& control & 39 & 4.41 & 0.96 & & & & \\
Application & experimental & 43 & 5.33 & 0.60 & 6.581 & 80 & $0.000^{* *}$ & 0.351 \\
& control & 39 & 4.05 & 1.09 & & & & \\
Reasoning & experimental & 43 & 7.37 & 0.69 & 13.106 & 80 & $0.000^{* *}$ & 0.682 \\
& control & 39 & 5.17 & 0.82 & & & & \\
total & experimental & 43 & 18.26 & 1.27 & 13.032 & 80 & $0.000^{* *}$ & 0.679 \\
& control & 39 & 13.64 & 1.89 & & & & \\
\hline
\end{tabular}

Table 8 shows that there are differences between the experimental and control groups in the means in the post application of the achievement test in favor of the experimental group. As shown in Table 8 the statistical significance of (T-test). This indicates that, there are statistically significant differences at $(\alpha \leq 0.01)$ between the scores means of experimental and control groups in the post application of achievement test in general, and in each of its dimensions alone in favor of the experimental group. To study the effectiveness, the (Eta-squared) was calculated. It is evident from Table 8 that the eta squared is greater than 0.2 , and the eta square indicates a significant effectiveness of the independent variable of brainstorming and inquiry-centered learning strategies in developing the dependent variable achievement in general and its dimensions separately.

\subsection{Creative Thinking Skills}

-The question: What is the effectiveness of the Inquiry and brainstorming strategies in developing creative thinking skills in the Arabic language among university students? To answer the current question, the following hypothesis has been formulated: There were statistically significant differences at $(\alpha \leq 0.01)$ between the scores means of experimental and control groups in the post application of creative thinking skills test in general, and in each of its dimensions alone in favor of the experimental group. Also, the means, standard deviations, and (t-test) value were calculated. The results were as shown in Table 9:

Table 9. Means, standard deviations and (t-test) to study the differences between the experimental and control groups in the post application of the creative thinking test

\begin{tabular}{|c|c|c|c|c|c|c|c|c|}
\hline dimensions & groups & $\mathrm{N}$ & means & Std. devotion & (t-test) & df. & Sig. & $\left(\eta^{2}\right)$ Eta squared \\
\hline \multirow[t]{2}{*}{ Fluency } & experimental & 43 & 49.79 & 2.83 & 30.868 & 80 & $0.000 * *$ & 0.922 \\
\hline & control & 39 & 27.08 & 3.80 & & & & \\
\hline \multirow[t]{2}{*}{ Flexibility } & experimental & 43 & 39.79 & 2.23 & 35.865 & 80 & $0.000 * *$ & 0.941 \\
\hline & control & 39 & 23.38 & 1.87 & & & & \\
\hline \multirow[t]{2}{*}{ Originality } & experimental & 43 & 22.05 & 2.49 & 24.603 & 80 & $0.000 * *$ & 0.883 \\
\hline & control & 39 & 8.08 & 2.25 & & & & \\
\hline \multirow[t]{2}{*}{ total } & experimental & 43 & 111.63 & 5.07 & 43.433 & 80 & $0.000 * *$ & 0.959 \\
\hline & control & 39 & 59.54 & 5.72 & & & & \\
\hline
\end{tabular}

Table 9 shows that there are differences between the experimental and control groups in the means in the post application of the creative thinking skills test in favor of the experimental group. And, Table 9 shows that there is statistical significance of (T-test). This indicates that there are statistically significant differences at $(\alpha \leq 0.01)$ between the scores means of experimental and control groups in the post application of creative thinking skills test in general, and in each of its skills alone in favor of the experimental group. To study the effectiveness of the brainstorming and inquiry-centered learning strategies, the (eta squared) was calculated. It is evident from Table 9 that the eta squared is greater than 0.2, and the eta square indicates a significant effectiveness of the independent variables brainstorming and inquiry-centered learning strategies in developing the dependent variable creative thinking skill in general and its dimensions separately.

The question: What is the relationship between university students' degrees in achievement in the Arabic language and their degrees in creative thinking skills? To answer the current question, the following hypothesis has been formulated: there is a positive, strong and statistically significant relationship at the level of $(\alpha \leq 0.01)$ between the scores of the experimental group students in the post application of achievement and creative thinking skills. Also, Pearson correlation coefficient was calculated to study the correlational relationship, and 
the results are as shown in Table 10:

Table 10. The Pearson correlation coefficient between achievement and creative thinking

\begin{tabular}{lllll}
\hline The relation & $\mathrm{N}$ & $\mathrm{R}$ & $\mathrm{Sig}$ & $\mathrm{R}^{2}$ \\
\hline achievement $\times$ creative thinking & 43 & 0.774 & $0.000^{* *}$ & 0.599 \\
\hline
\end{tabular}

Table 10 shows that, there are positive and storing relation between the scores of post application of achievement in the Arabic language and their degrees in creative thinking skills at students of experimental group. This indicates that there are a positive, strong and statistically significant relationship at the level of $(\alpha \leq 0.01)$ between the scores of the experimental group students in the post application of achievement and creative thinking skills. To study the effectiveness of the relationship between the two variables, the coefficient of determination was calculated. It turns out that the ratio of the determination coefficient is equal to $(59.9 \%)$ and indicates that the achievement variable and the creative thinking skills variable explain each other by an equal ratio $(59.9 \%)$.

\section{Discussion}

The results of the current study showed the effectiveness of using Inquiry and brainstorming strategies for teaching Arabic in developing academic achievement and creative thinking skills among preparatory year students at King Khalid University in the Kingdom of Saudi Arabia. The results of the current study are referred to many reasons, including that inquiry learning guides students towards employing conceptual and procedural knowledge in an applied manner Vreman-de, Ton and Gijlers (2013). In addition, the study of Dole (2013) showed the effectiveness of the survey in developing many skills among students, such as: formulating and posing questions, imposing hypotheses, collecting data and information from various sources, discussing solutions and alternatives, testing them, evaluating solutions, writing process, and building inferences. These processes are of great importance for developing creative thinking skills.

Also, a study of Al-Zahrani (2015) emphasizes the necessity of choosing teaching strategies that transform the student from passive to active in the educational situation. Inquiry-centered learning and brainstorming strategies transform the student from passive to active. In addition, a study of Deejring (2016) showed that developing creative thinking skills among university students is related to student-centered teaching strategies, including educational projects that aim to develop experimentation, investigation and problem-solving processes. It is noted that the learning strategies centered on inquiry and brainstorming are among the strategies that support students in learning, imposing hypotheses, and proposing various ideas, and these processes enhance the development of students' creative thinking skills, as well as improve students' levels of academic achievement.

The results of the study Jastrzębska and Limont (2017) also showed the importance of the creative environment in developing creative thinking skills. The creative environment consists of open learning experiences and flexible teaching strategies that support students in thinking, with an emphasis on open discussion processes, brainstorming, and creative writing skills. The creative environment also includes positive interactions and effective communication between the students and the teacher.

In addition, Valentová and Brečka (2020) explained that non-traditional student-centered teaching strategies enhance the development of thinking skills, and support students in improving academic achievement levels. For several reasons, these non-traditional strategies focus on mental and performance processes. This strategy emphasizes students' levels of attention, motivation and persistence in learning.

In addition, the effectiveness of using inquiry in learning communities and during classroom discussions enhances student motivation to participate and be responsible in designing educational experiences and activities. Inquiry-centered learning is associated with various levels that differ in light of the level of employability of self-learning, levels of communication between teacher and student, discussion sessions and brainstorming. These levels can be used according to academic subjects (Svendsen, 2020). Also, the use of a brainstorming strategy stimulates students in generating ideas and solutions, while evaluating and developing thinking pathways (Mentzer, Farrington, \& Tennenhouse, 2015).

\section{Conclusion}

The main goal of this study is investigated the effectiveness the inquiry and brainstorming strategies in teaching Arabic language, and the relation between the achievement and creative thinking skills. The study aimed to answer the questions, 1) how can inquiry and brainstorming strategies be used in teaching Arabic to develop 
achievement and creative thinking skills for university students? 2) What is the effectiveness of the inquiry and brainstorming strategies in developing achievement in the Arabic language among university students? 3) What is the effectiveness of the inquiry and brainstorming strategies in developing creative thinking skills in the Arabic language among university students, 4) What is the relationship between university students' degrees in achievement in the Arabic language and their degrees in creative thinking skills?

Through the application of the inquiry and brainstorming learning strategies in teaching the language skills course to the preparatory year students in the experimental group, and teaching the language skills course to the preparatory year students in the control group using traditional strategies, it was found: There were statistically significant differences at $(\alpha \leq 0.01)$ between the scores means of experimental and control groups in the post application of achievement test in general, and in each of its dimensions alone in favor of the experimental group Also, there were statistically significant differences at $(\alpha \leq 0.01)$ between the scores means of experimental and control groups in the post application of creative thinking skills test in general, and in each of its dimensions alone in favor of the experimental group. The effectiveness of the investigation and brainstorming strategies in developing achievement and creative thinking skills in the language skills course was demonstrated by using the eta squared. In addition, there is a positive, strong and statistically significant relationship at the level of ( $\alpha \leq$ 0.01 ) between the scores of the experimental group students in the post application of achievement and creative thinking skills.

The current study recommended that, using the strategies of brainstorming and inquiry in teaching Arabic language is very necessary, so the professional development program including these strategies will be prepared to develop performance of university faculty members. The study also suggested that the evaluating the teaching performance and teaching practices of university faculty members in light of the using inquiry and brainstorming strategies is important, Therefore, many studies and applied research can be designed to develop teaching performance in the fields of language.

\section{References}

Al-Zahrani, A. (2015). From passive to active: The impact of the flipped classroom through social learning platforms on higher education students' creative thinking. British Journal of Educational Technology, 46(6), 1133-1148. https://doi.org/10.1111/bjet.12353

Anjarwati, P., Sajidan, S., \& Prayitno, B. (2018). Problem-Based Learning Module of Environmental Changes to Enhance Students' Creative Thinking Skill. Biosaintifika: Journal of Biology \& Biology Education, 10(2), 313-319. https://doi.org/10.15294/biosaintifika.v10i2.12598

Baker, W., Barstack, R., Clark, D., Hull, E., Goodman, B., Kook, J., ... Lang, M. (2008). Writing-to-Learn in the Inquiry-Science Classroom: Effective Strategies from Middle School Science and Writing Teachers. Clearing House, 81(3), 105-108. https://doi.org/10.3200/TCHS.81.3.105-108

Carstens, L., \& Howell, J. (2012). Questions that matter: Using inquiry-guided faculty development to create an inquiry-guided learning curriculum. New Directions for Teaching \& Learning, 2012(129), 51-59. https://doi.org/10.1002/tl.20006

Coles, A., \& Banfield, G. (2012). Creativity and Mathematics: Using Learning Journals. Mathematics Teaching, $228,6-11$.

Coskun, H., \& Gocmen, Ö. (2019). Individual Brainstorming Performance as a Function of Velocity and Comparison Feedback. Dokuz Eylul University Journal of Graduate School of Social Sciences, 21(1), 197-210. https://doi.org/10.16953/deusosbil.322058

Deejring, K. (2016). The design of Knowledge management to develop creative thinking for higher education with project base learning. Proceedings of the Multidisciplinary Academic Conference, 63-70, 167-183.

Dole, L. (2013). Using Inquiry Groups to Meet the Next Generation Science Standards. Library Media Connection, 32(2), 34-36.

Dunlap, L., \& Antonio, R. (2012). A Blended Multisite Distance Workshop in Mathematics Using Inquiry, Technology and Collaboration: Discrete Mathematics and Statistics. Electronic Journal of Mathematics \& Technology, 6(2), 196-215.

Evans, M., \& Lange, A. (2019). Supporting Student Activists: An Appreciative Inquiry. New Directions for Student Leadership, 2019(161), 65-77. https://doi.org/10.1002/yd.20321

Jastrzębska, D., \& Limont, W. (2017). Not Only Jumps, Slumps, but also Mini Plateau. Creative Potential Assessed by the Test for Creative Thinking-Drawing Production. A Cross-Sectional Study of Polish 
Students Aged from 7 to 18. Creativity Research Journal, 29(3), 337-342. https://doi.org/10.1080/10400419.2017.1360060

Kiili, C., Coiro, J., \& Räikkönen, E. (2019). Students' evaluation of information during online inquiry: Working individually or in pairs. Australian Journal of Language \& Literacy, 42(3), 9-11.

McCarthy, J. (2018). Do Creative Thinking and Creative Problem-Solving Have a Place in Counseling Curricula? Journal of Creativity in Mental Health, 13(3), 306-317. https://doi.org/10.1080/15401383.2018.1433092

Memory, D., Yoder, C., Bolinger, K., \& Warren, W. (2004). Creating Thinking and Inquiry Tasks that Reflect the Concerns and Interests of Adolescents. Social Studies, 95(4), 147-154. https://doi.org/10.3200/TSSS.95.4.147-154

Mentzer, N., Farrington, S., \& Tennenhouse, J. (2015). strategies for teaching brainstorming in design education. Technology \& Engineering Teacher, 74(8), 8-13.

Mohammed, H. (2015). A Program Based on Task-Based Teaching Approach to Develop Creative Thinking Teaching Skills for Female Science Teachers in Kingdom of Saudi Arabia (Ksa). Education, 136(1), 24-33.

Moses, L., Busetti, R., \& Pritchard, R. (2015). Inquiry as ESL. Reading Teacher, 68(6), 435-447. https://doi.org/10.1002/trtr.1333

Nogueira, S., Almeida, L., \& Lima, T. (2017). Two Tracks of Thought: A Structural Model of the Test for Creative Thinking-Drawing Production (TCT-DP). Creativity Research Journal, 29(2), 206-211. https://doi.org/10.1080/10400419.2017.1303312

Ormond, B. (2011). Enabling Students to Read Historical Images: The Value of the Three-Level Guide for Historical Inquiry. History Teacher, 44(2), 179-190.

Paula, M., \& Wingate, E. (2014). Using Inquiry to Learn about Soil: A Fourth Grade Experience. Science Activities, 51(3), 89-100. https://doi.org/10.1080/00368121.2014.899554

Pittman, J. (2011). Inquiry-based Math in School Gardens. Connect Magazine, 24(5), 4-7.

Ritter, S., Gu, X., Crijns, M., \& Biekens, P. (2020). Fostering students' creative thinking skills by means of a one-year creativity training program. PLoS ONE, 15(3), 1-18. https://doi.org/10.1371/journal.pone.0229773

Robson, S. (2014). The Analysing Children's Creative Thinking framework: development of an observation-led approach to identifying and analysing young children's creative thinking. British Educational Research Journal, 40(1), 121-134. https://doi.org/10.1002/berj.3033

Sak, U., \& Maker, C. (2006). Developmental Variation in Children's Creative Mathematical Thinking as a Function of Schooling, Age, and Knowledge. Creativity Research Journal, 18(3), 279-291. https://doi.org/10.1207/s15326934crj1803_5

Svendsen, B. (2020). Inquiries into Teacher Professional Development-What Matters? Education, 140(3), $111-130$.

Tomcho, T., Foels, R., Rice, D., Johnson, J., Moses, T., Warner, D., ... Amalfi, T. (2008). Review of ToP Teaching Strategies: Links to Students' Scientific Inquiry Skills Development. Teaching of Psychology, 35(3), 147-159. https://doi.org/10.1080/00986280802201976

Vale, C., Bragg, L. A., Widjaja, W., Herbert, S., \& Esther, Y.-K. L. (2017). Children's mathematical reasoning: Opportunities for developing understanding and creative thinking. Australian Primary Mathematics Classroom, 22(1), 3-8.

Valentová, M., \& Brečka, P. (2020). Ways of Critical and Creative Thinking Development in Practical Training through Video-Study. TEM Journal, 9(1), 327-334.

Vreman-de, C., Ton, D., \& Gijlers, H. (2013). Learning by Designing Instruction in the Context of Simulation-based Inquiry Learning. Journal of Educational Technology \& Society, 16(4), 47-58.

Yarbrough, N. (2016). Assessment of Creative Thinking Across Cultures Using the Torrance Tests of Creative Thinking (TTCT): Translation and Validity Issues. Creativity Research Journal, 28(2), 154-164. https://doi.org/10.1080/10400419.2016.1162571 


\section{Copyrights}

Copyright for this article is retained by the author, with first publication rights granted to the journal.

This is an open-access article distributed under the terms and conditions of the Creative Commons Attribution license (http://creativecommons.org/licenses/by/4.0/). 